\title{
Análise da qualidade do relatório de impacto sobre o meio ambiente de um terminal portuário do Município de Itacoatiara/AM
}

Quality analysis of the environmental impact report of a port terminal in the Municipality of Itacoatiara/AM

Análisis de calidad del informe de impacto ambiental de una terminal portuaria del Municipio de Itacoatiara/AM

Recebido: 26/07/2021 | Revisado: 31/07/2021 | Aceito: 03/08/2021 | Publicado: 08/08/2021

\author{
Gabriel dos Anjos Guimarães \\ ORCID: https://orcid.org/0000-0002-4491-9727 \\ Universidade Federal do Amazonas, Brasil \\ E-mail: gaguimaraes09@gmail.com \\ Rodrigo Couto Alves \\ ORCID: https://orcid.org/0000-0002-7452-9455 \\ Universidade Federal do Amazonas, Brasil \\ E-mail: rcouto@ufam.edu.br
}

\begin{abstract}
Resumo
O presente estudo teve como objetivo realizar uma análise qualitativa do relatório de impacto sobre o meio ambiente (RIMA) de um terminal portuário localizado no município de Itacoatiara/AM. O relatório foi analisado de acordo com os parâmetros mínimos estabelecido pelo Art. 9 da Resolução CONAMA nº 01/1986 que dispõe critérios mínimos para elaboração do RIMA. Foi realizada uma síntese geral dos requisitos analisados. Foi possível observar que o relatório possui diversas palavras de cunho técnico que dificultam o entendimento e a clareza. O RIMA apresenta objetivos e justificativas coerentes e com ótima qualidade. Dessa mesma maneira, as alternativas e o diagnóstico ambiental do empreendimento estão de acordo em sua maioria com a Resolução CONAMA. Por outro lado, há deficiência nos impactos ambientais, onde não são caracterizados nas fases da instalação e da operação. Não foram consideradas as diferentes situações e suas alternativas, bem como à não execução do empreendimento. As medidas mitigadoras são apresentadas de forma clara e objetivas, porém não foram apresentados programas suficientes. Por fim, a conclusão não está coerente com a realidade do empreendimento, bem como a equipe multidisciplinar, onde não há uma variedade de profissionais. De forma geral, 60\% dos requisitos salientados pela Resolução CONAMA não estavam de acordo, enquanto que $40 \%$ estavam relativamente dentro das recomendações. Sendo assim, o presente estudo apresenta dados que mostram a qualidade do RIMA que, com a ausência dessas informações é possível ocorrer danos sobre o meio ambiente, bem como falta do entendimento ao público leigo.
\end{abstract}

Palavras-chave: Estudos ambientais; Impactos ambientais; Público leigo.

\begin{abstract}
This study aimed to carry out a qualitative analysis of the environmental impact report (RIMA) of a port terminal located in the municipality of Itacoatiara/AM. The report was analyzed according to the minimum parameters established by Article 9 of CONAMA Resolution No. 01/1986, which provides for minimum criteria for preparing the RIMA. A general synthesis of the analyzed requirements was carried out. It was possible to observe that the report has several technical words that make understanding and clarity difficult. RIMA presents coherent objectives and justifications, with excellent quality. In this way, the alternatives and the environmental diagnosis of the project are mostly in accordance with the CONAMA Resolution. On the other hand, there is a deficiency in environmental impacts, which are not characterized in the installation and operation phases. The different situations and their alternatives were not considered, as well as the non-execution of the project. The mitigating measures are presented in a clear and objective way, but not enough programs were presented. Finally, the conclusion is not consistent with the reality of the project, as well as the multidisciplinary team, where there is not a variety of professionals. Overall, 60\% of the requirements highlighted by the CONAMA Resolution were not in agreement, while $40 \%$ were relatively within the recommendations. Thus, this study presents data that show the quality of RIMA that, in the absence of this information, damage to the environment is possible, as well as a lack of understanding for the lay public.
\end{abstract}

Keywords: Environmental studies; Environmental impacts; Lay public. 


\begin{abstract}
Resumen
Este estudio tuvo como objetivo realizar un análisis cualitativo del informe de impacto ambiental (RIMA) de una terminal portuaria ubicada en el municipio de Itacoatiara / AM. El informe fue analizado de acuerdo con los parámetros mínimos establecidos por el artículo 9 de la Resolución CONAMA No. 01/1986, que establece los criterios mínimos para la elaboración del RIMA. Se realizó una síntesis general de los requerimientos analizados. Se pudo observar que el informe tiene varias palabras técnicas que dificultan la comprensión y la claridad. RIMA presenta objetivos y justificaciones coherentes, con excelente calidad. De esta manera, las alternativas y el diagnóstico ambiental del proyecto están mayoritariamente de acuerdo con la Resolución de CONAMA. Por otro lado, existe una deficiencia en los impactos ambientales, los cuales no se caracterizan en las fases de instalación y operación. No se consideraron las diferentes situaciones y sus alternativas, así como la no ejecución del proyecto. Las medidas de mitigación se presentan de manera clara y objetiva, pero no se presentaron suficientes programas. Finalmente, la conclusión no es acorde con la realidad del proyecto, así como la del equipo multidisciplinar, donde no hay variedad de profesionales. En general, el $60 \%$ de los requisitos destacados por la Resolución de CONAMA no estaban de acuerdo, mientras que el $40 \%$ estaban relativamente dentro de las recomendaciones. Así, este estudio presenta datos que demuestran la calidad de RIMA que, en ausencia de esta información, es posible el daño al medio ambiente, así como una falta de comprensión por parte del público lego.
\end{abstract}

Palabras clave: Estudios ambientales; Impactos ambientales; Público laico.

\title{
1. Introdução
}

O setor portuário corresponde à principal entrada e saída de produtos de um país. Com a globalização, os terminais portuários tornaram-se os principais subsídios do sistema logístico em suprir às demandas dos mercados nacionais e internacionais, por meio da possibilidade de movimentar quantidades significativas de cargas, além da elevada contribuição para redução dos custos operacionais (Monié \& Vidal, 2006; Guedes et al., 2008; Moura \& Botter, 2011).

Os impactos socioeconômicos das atividades portuárias são relacionados em ganhos comerciais e na geração de empregos, que afetam diretamente a estruturação de uma comunidade e a relação do espaço natural a que ocupam. Entretanto, esta mesma atividade proporciona em impactos ambientais relacionados pela desarmonia da organização sobre o meio ambiente (Oliveira, 2015).

Desta forma, o setor portuário é de extrema importância para o desenvolvimento socioeconômico de uma nação. Por outro lado, apesar dos benefícios dos terminais portuários, há diversos problemas relacionados com a geração de impactos ambientais oriundo das atividades portuárias, a exemplo: poluição do ar gerado pela movimentação de navios, veículos e entre outros; geração de diversos tipos de resíduos no empreendimento; erosões do solo; alteração da qualidade da água; e entre outros (Bertoloto \& Mello, 2011; Mohee et al., 2012).

A preocupação com os problemas ambientais está relacionada diretamente com o presente estado de conservação do meio ambiente, originando um aumento nas pesquisas desenvolvidas e dos conhecimentos adquiridos. As responsabilidades sobre a conservação do meio ambiente, fazem parte tanto dos renomeados pesquisadores da área, em esmagadora maioria, da academia e, também, da corporação dos grandes empreendimentos mundiais, no qual, a área de discussão está ganhando espaço com governantes, organizações e sociedade como um todo (Pinheiro et al., 2014).

Sendo assim, a Resolução do Conselho Nacional do Meio Ambiente (CONAMA) nº 01/1986 (Brasil, 1986) salienta a importância da avaliação de impactos ambientais em empreendimentos, sendo fundamental à devida importância com a realização de estudos de impactos ambientais e relatórios de impactos sobre o meio ambiente para qualquer empreendimento, além da informação prestada ao público afetado direto e indiretamente pela obra.

A partir disso, o terminal portuário está situado no município de Itacoatiara, no estado do Amazonas. O empreendimento, quando concluído, englobará um conjunto de quatro terminais específicos em 3 píeres, dedicados à movimentação de granéis líquidos: Terminal de Granéis Líquidos (TGL); de minérios: Terminal de Granéis Sólidos Minerais (TGSM); de granéis sólidos agrícolas: Terminal de Granéis Sólidos Agrícolas (TGSA); e de carga geral: Terminal de Carga Geral (TCG). Sendo estes dois últimos terminais instalados em um único píer (Tpnr, 2015). 
A qualidade do estudo de impacto ambiental e seu respectivo relatório de impacto sobre o meio ambiente (EIA/RIMA), representa informações para uma grande tomada de decisão referente a necessidade da mitigação e implantação de estratégias a serem utilizadas na avaliação de impactos ambientais de um determinado projeto (Sánchez, 2013).

As metodologias para avaliação dos impactos ambientais são de suma importância e visam: identificar, avaliar e sintetizar os danos ocasionados por um projeto ou programa nas áreas de alcance ambiental de um empreendimento (Eletronuclear, 2005). Além disso, outro fator aliado a avaliação de impactos ambientais é o acesso das informações ambientais, sendo um direito do cidadão previsto na Lei Federal n ${ }^{\circ}$ 10.650/2003 que dispõe sobre o acesso público aos dados e informações existentes nos órgãos e entidades integrantes do Sistema Nacional do Meio Ambiente (SISNAMA) (Brasil, 2003), necessitando estas, a possuírem qualidades suficientes, que permitam o acompanhamento pela sociedade das alterações ambientais.

Sendo assim, o RIMA tem como objetivo principal informar à população sobre os principais resultados e conclusões do EIA, além de fornecer informações claras sobre quais serão os objetivos, justificativas, as alternativas e os motivos das opções concretizadas pelos técnicos para implantação do empreendimento e os planos e programas para mitigação ou compensação dos impactos negativos. Salienta-se mais uma vez, que a legislação descreve a importância da informação ao público para a legalidade do processo de licenciamento (Scheidecker, 2018).

Diante deste exposto, o presente estudo teve como objetivo realizar uma análise qualitativa do relatório de impacto sobre o meio ambiente (RIMA) de um terminal portuário localizado no município de Itacoatiara, no Amazonas, colocando em questão a qualidade do documento e se esse atende de forma clara e objetiva às questões a que se propõe, sob a ótica da legislação ambiental e de informação ao público leigo.

\section{Metodologia}

A metodologia utilizada foi dividida em: a) Universo de estudo; e b) Coleta e análise de dados.

\subsection{Universo de estudo}

O distrito de Novo Remanso está situado na zona rural do município de Itacoatiara, no Estado do Amazonas, tendo seus limites estabelecidos: ao Norte com o Município de Itapiranga, ao Sul com o Município de Autazes, a Leste com Urucurituba e a Oeste com o Município de Rio Preto da Eva. No ano de 2010, o município possuía uma população de 86.839 habitantes, com uma estimativa para o ano de 2020 de 102.701 habitantes, e sua área territorial em 2016 era de 8.891,906 km². Quanto ao distrito de Novo Remanso, este possuía em 2010 uma população de 3.439 habitantes (Ibge, 2021).

O acesso ao terminal portuário se dá por meio de um percurso de 100 quilômetros pela rodovia AM-010 a partir da barreira municipal da cidade de Itacoatiara até a interseção com a estrada de acesso à Novo Remanso. Deste ponto, o trajeto se dá com andamento de 40 quilômetros pela estrada de Novo Remanso até o Ramal do Macaco Cego. O trajeto é complementado por mais 9 quilômetros por vias rurais não pavimentadas, dentro da propriedade do Terminal Portuário (Tpnr, 2015). A Figura 1 apresenta a localização do Terminal Portuário. 
Figura 1: Localização do Terminal Portuário.

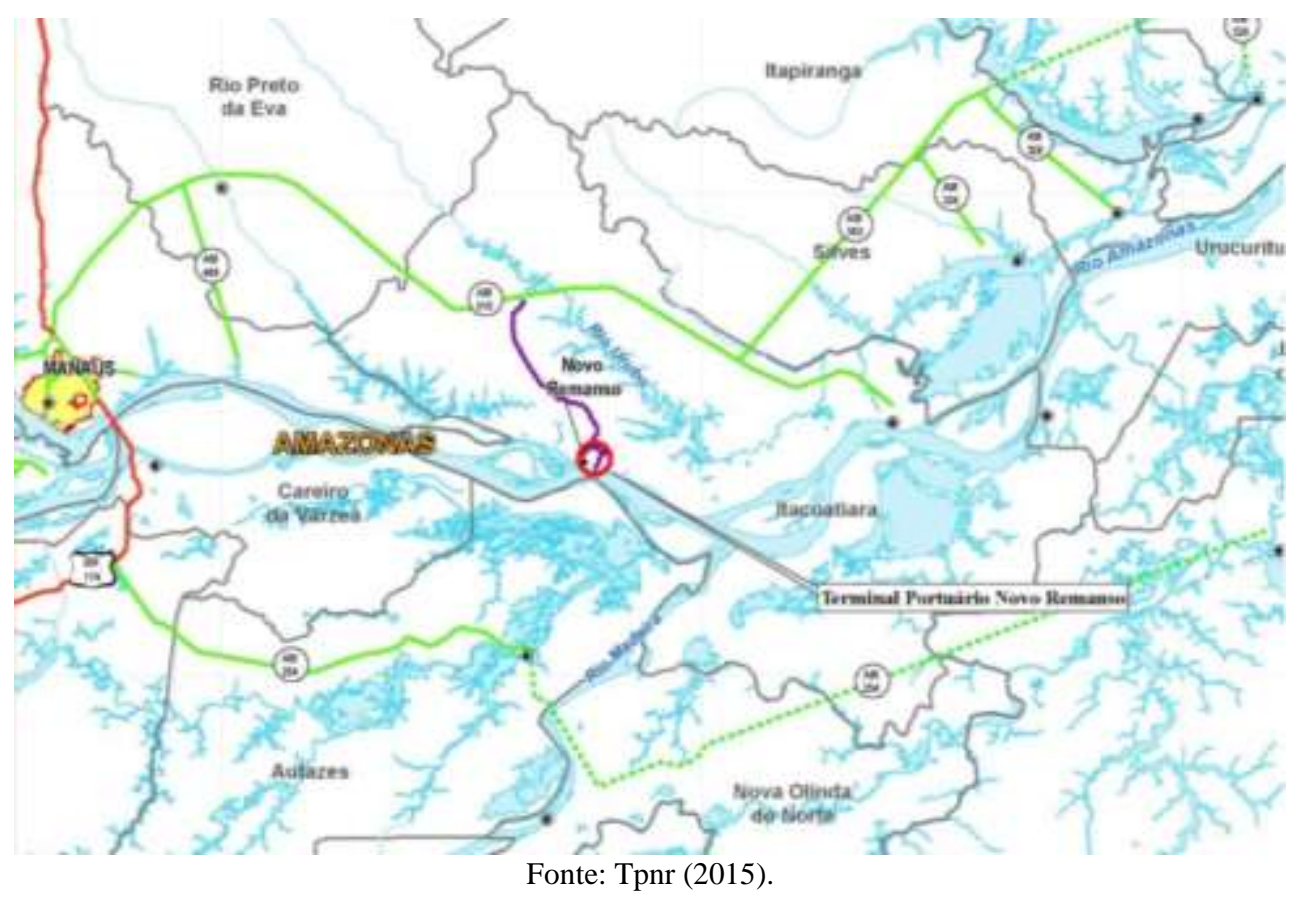

\subsection{Tipo de pesquisa}

O presente estudo aborda uma pesquisa de caráter descritivo, onde apresenta fatos ou eventos por meio de registros, análises, ordenamentos e descrição sem sua modificação, além de agregar no descobrimento da frequência em que os eventos ou fatores ocorrem, sua natureza, suas propriedades, motivos e semelhança (Sakamoto \& Silveira, 2014).

A metodologia deste trabalho se caracteriza, de acordo com a sua natureza, como qualitativa, pois considera um meio indissociável entre o mundo real e o sujeito que não pode ser apresentado em números. Esta natureza apresenta dados descritivos, apresentando um maior número de informações presentes na área estudada (Prodanov \& Freitas, 2013).

Quanto às técnicas de pesquisa reunidas em Marconi \& Lakatos (2003), o levantamento e obtenção de dados serão por documentação indireta, através de pesquisa bibliográfica.

\subsection{Coleta e análise de dados}

A metodologia do presente estudo abrange a seleção dos critérios apresentados para a avaliação qualitativa do documento referente ao Relatório de Impacto sobre o Meio Ambiente do Terminal Portuário localizado no município de Itacoatiara/AM (Tpnr, 2015). O documento supracitado foi disponibilizado exclusivamente via site do Instituto de Proteção Ambiental do Amazonas (IPAAM), na qual disponibiliza EIA/RIMAs ao púbico em geral.

Com intuito de analisar a qualidade do documento em relação as informações prestadas ao público leigo e demais profissionais, foi tomado como base toda estrutura apresentada no documento, na qual foi determinado pontos chaves e analisados e discutidos, na promoção da qualidade do documento ofertado ao público.

Desta forma, o presente relatório foi analisado de acordo com os parâmetros mínimos estabelecido pelo Art. 9 da resolução CONAMA ño 01/1986 (Brasil, 1986) que dispõe critérios mínimos que o RIMA deverá conter. O Quadro 1 apresenta os parâmetros da qualidade do relatório de impacto sobre o meio ambiente que foram analisados no presente estudo. 
Quadro 1: Parâmetros da qualidade do relatório de impacto sobre o meio ambiente.

\begin{tabular}{|c|c|}
\hline Requisitos Analisados & Mensuração dos requisitos \\
\hline Linguagem & $\begin{array}{l}\text { Análise da presença ou ausência do glossário e identificação de } \\
\text { palavras técnicas de difícil compreensão, nos meios físico, biótico e } \\
\text { antrópico do RIMA. }\end{array}$ \\
\hline Objetivos e Justificativas & Verificação da coerência e qualidade dos objetivos e justificativa. \\
\hline Empreendimento & $\begin{array}{l}\text { Análise das alternativas tecnológicas, locacionais e configuração da } \\
\text { obra. }\end{array}$ \\
\hline Diagnóstico Ambiental & $\begin{array}{l}\text { Avaliação da clareza na caracterização dos meios físico, biótico e } \\
\text { socioeconômico. }\end{array}$ \\
\hline Prováveis Impactos Ambientais & $\begin{array}{l}\text { Análise dos impactos ambientais apresentados no RIMA, bem como } \\
\text { a veracidade conforme em outros RIMAs. }\end{array}$ \\
\hline $\begin{array}{l}\text { Qualidade ambiental futura da área } \\
\text { de influência }\end{array}$ & $\begin{array}{l}\text { Avaliação das diferentes situações do empreendimento e suas } \\
\text { alternativas, bem como à não execução do empreendimento. }\end{array}$ \\
\hline Medidas mitigadoras & $\begin{array}{l}\text { Análise da qualidade das prováveis medidas mitigadoras para o } \\
\text { empreendimento. }\end{array}$ \\
\hline $\begin{array}{l}\text { Programa de acompanhamento e } \\
\text { monitoramento dos impactos }\end{array}$ & $\begin{array}{l}\text { Análise da qualidade e eficiência dos programas ambientais } \\
\text { propostos. }\end{array}$ \\
\hline Conclusões & $\begin{array}{l}\text { Avaliação da objetividade, clareza e coerência das conclusões do } \\
\text { empreendimento. }\end{array}$ \\
\hline Equipe Multidisciplinar & $\begin{array}{l}\text { Determinação da existência de pluralidade entre os profissionais } \\
\text { formadores da equipe. }\end{array}$ \\
\hline
\end{tabular}

Fonte: Brasil (1986).

Ainda, após a análise dos requisitos mínimos que um relatório deverá conter, foi realizado uma síntese geral dos requisitos analisados de acordo com Oliveira (2018). Foram atribuídas duas palavras, sendo "Não" e "Sim", correspondente a pelo menos um dos requisitos não foram cumpridos e todos os requisitos foram cumpridos de acordo com as legislações ambientais, respectivamente.

A análise dos critérios presente no RIMA foi realizada por meio de uma leitura interpretativa de revisões bibliográficas e documentos legais baseados na avaliação da qualidade do relatório de impacto sobre o meio ambiente. Sendo assim, o presente relatório foi analisado e discutido criticamente por meio da Resolução CONAMA nº 01/1986 (Brasil, 1986), Lei $\mathrm{n}^{\circ}$ 10.650, que dispõe sobre o acesso público aos dados e informações existentes nos órgãos e entidades integrantes do Sisnama (Brasil, 2003) e demais RIMAs sobre terminal portuário.

\section{Resultados e Discussão}

Os resultados foram divididos em duas etapas: a) Análise dos critérios selecionados; e b) Síntese geral dos requisitos analisados.

\subsection{Análise dos critérios selecionados}

\subsubsection{Linguagem}

A primeira etapa da análise constituiu-se na verificação da linguagem presente no corpo do texto do RIMA do Terminal Portuário. Foi observado de modo geral, que o corpo do texto presente no RIMA possui uma linguagem objetiva, porém em certos momentos possui ausência de clareza, relacionado diretamente com a existência de diversas palavras técnicas que não são explicadas no decorrer do texto ou em glossário, comprometendo a compreensão dos leitores.

O presente RIMA não apresenta um glossário ou lista de significados das siglas ou termos que são incomuns para o público leigo, sendo uma problemática enfrentada em diversos outros RIMAs referente a terminais portuários, a exemplo do Terfron (2005) e Ldc (2020). O Quadro 2 apresenta as palavras técnicas utilizadas nos meios físico, biótico e socioeconômico. 
Quadro 2: Palavras técnicas de difícil compreensão para o meio físico, biótico e socioeconômico.

\begin{tabular}{|c|c|c|}
\hline Meio Físico & Meio Biótico & Meio Socioeconômico \\
\hline Aluvionares & & \\
Fertilidade natural & & Escoamento \\
Escarpas & & Poços profundos \\
Solapamento & UTE \\
Erosão & Biomas & Potência instalada \\
Microbacias & Ordens & Esgotamento sanitário \\
Recarga/nascente & Famílias & Fossas sépticas \\
Planície & Endêmicas & Fossas rudimentares \\
Características físicas & & Resíduos domésticos \\
Características químicas & & Arqueológico \\
Características bacteriológicas & & \\
Características biológicas & & \\
\hline
\end{tabular}

Fonte: Autores (2021).

A Resolução CONAMA nº 01/1986 (Brasil, 1986) salienta que as informações contidas nos relatórios ambientais devem ser traduzidas em linguagem compreensível, sendo essencial a utilização de mapas, quadros, gráficos e demais ferramentas que promova o acesso ao entendimento para o público leigo, referente aos impactos socioeconômicos e ambientais que empreendimento poderá causar (Brasil, 1986). Foi observado no presente RIMA que há diversas palavras de cunho técnico que dificultam o entendimento e a clareza do relatório, que de certa forma, poderia ser minimizado com a inclusão de um glossário, quadros, gráficos e outros para facilitar a compreensão da linguagem ao público leigo.

\subsubsection{Objetivos e justificativas}

Segundo a Resolução CONAMA nº 01/1986 (Brasil, 1986), os objetivos e justificativas são de suma importância principalmente em relação e compatibilidade com as políticas setoriais, planos e programas governamentais.

Diante deste contexto, o objetivo do RIMA é:

Atender a demanda atual e crescente por infraestrutura portuária em uma hidrovia de importância socioeconômica consolidada, de forma a servir como nova alternativa à movimentação de cargas que já são transportadas pela hidrovia Solimões-Amazonas em sua porção ocidental (Tpnr, 2015, p. 4).

Por outro lado, para justificar a instalação do empreendimento no distrito de Novo Remanso foi considerado que:

O local onde o TPNR é proposto está situado a aproximadamente 30 quilômetros da foz do rio Madeira, ou seja, está posicionado em local estratégico, junto aos dois principais corredores hidroviários brasileiros. Além disso, o local possui todas as condições para operações de transbordo de cargas entre navios de grande porte, como os do tipo Panamax, e barcaças ou barcos regionais, adequados à navegação em rios de menor profundidade, através dos quais é possível alcançar cidades e portos em diferentes pontos da Amazônia. (Tpnr, 2015, p. 3).

Segundo a Agência Nacional de Transportes Aquaviários (Antaq, 2013) a maior hidrovia brasileira em distância percorrida e em volume de cargas é a Solimões-Amazonas. Além disso, a mesma possui ligação direta com o Oceano Atlântico e com os rios Madeira e Tocantins, favorecendo a utilização para desenvolvimento da econômica local e nacional, por meio dos transportes hidroviários de cargas.

É notório a importância da movimentação de cargas em hidrovias brasileiras, na qual, além de promover o desenvolvimento sustentável e socioeconômico de uma região, agrega com o transporte de carga que são essenciais, tendo em consideração a disponibilidade hídrica para a movimentação.

Salienta-se a importância do empreendimento analisado, para o crescimento socioeconômico do município de Itacoatiara e arredores, bem como suprir as necessidades municipais e estaduais do país por meio do transporte de cargas 
granéis líquidos (combustíveis), granéis agrícolas (soja, milho, farelo), granéis minerais (minérios e fertilizantes) e de carga geral.

\subsubsection{Alternativas tecnológicas, locacionais e configuração do empreendimento}

A Resolução CONAMA nº 01/86 em seu art. 9 (Brasil, 1986), preconiza que o relatório de impacto ambiental deve conter as descrições do projeto e suas alternativas tecnológicas e locacionais:

Especificando para cada um deles, nas fases de construção e operação a área de influência, as matérias primas, e mãode-obra, as fontes de energia, os processos e técnica operacionais, os prováveis efluentes, emissões, resíduos de energia, os empregos diretos e indiretos a serem gerados (Brasil, 1986, art. 9).

O presente RIMA apresenta diversas vantagens nas alternativas técnicas que são destinadas a movimentação de carga por meio de hidrovias e rodovias:

Na comparação com o modal rodoviário, por exemplo, o transporte hidroviário apresenta eficiência energética (relação carga/potência) 29 vezes superior, um consumo de combustível 19 vezes menor, além de emitir 6 vezes menos CO2 e 18 vezes menos NO (Tpnr, 2015, p. 7).

Desta forma, é possível observar a vantagem na utilização do transporte de cargas por meio de hidrovias, minimizando os impactos ambientais. Por outro lado, é possível descrever que há desvantagens na movimentação de cargas por meio de rodovias e ferrovias como erosões, corte da vegetação, terraplanagem em logos percursos, desapropriação de terras e outros que mostram a essencialidade da utilização de hidrovias para o transporte de carga na região amazônica (Tpnr, 2015).

Quanto as alternativas locacionais, foi observado no RIMA que o terminal analisou somente uma área, na qual foi destinada a sócios do próprio TPNR em 1980:

O empreendimento é proposto em imóvel rural de propriedade da empresa Terminal Portuário Novo Remanso S/A. Denominada Fazenda Carabao, este imóvel foi adquirido pelos fundadores e sócios da Terminal Portuário Novo Remanso S/A na década de 1980, sendo utilizado para atividades de pecuária extensiva e outras atividades tipicamente rurais desde meados da década de 1960 (Tpnr, 2015, p. 8).

Observa-se que a área na qual será construída o terminal já passou por outras atividades, como a pecuária. O RIMA mostra que não foi considerado demais áreas para instalação do empreendimento, uma vez que esta área está localizada em ponto estratégico para a movimentação de grandes cargas (Tpnr, 2015).

Para todas as alternativas analisadas no presente RIMA, foi observado que nenhuma apresentou as áreas de influência, fontes de energia, processos e técnica operacionais, prováveis efluentes, emissões e resíduos de energia, sendo requisitos mínimos e obrigatórios para elaboração do RIMA de acordo com a Resolução CONAMA nº 01/1986 (Brasil, 1986).

Longe desta realidade, o RIMA de um Terminal no Rio Pará (Ldc, 2020), selecionou algumas alternativas técnicas para o sistema de carregamento e descarregamento de navios (Ldc, 2020). Quanto as alternativas locacionais, alguns RIMAs consideraram três alternativas que buscam minimizar os potenciais impactos socioambientais sobre as áreas de influência referente a implantação (Ldc, 2020; Bc port, 2016). Foi observado no presente RIMA a ausência de informações referente as alternativas técnicas e locacionais, sendo uma problemática que prejudica a qualidade do documento.

O empreendimento será configurado por meio de 4 (quatro) terminais em 3 (três) píeres, sendo um terminal de Granéis Sólidos Agrícolas (soja em grãos e milho em grãos), um Terminal de Granéis Líquidos (gasolina Tipo "C", óleo pesado, óleo diesel marítimo, óleo diesel metropolitano, álcool etílico hidratado e querosene de aviação), um Terminal de Granéis Sólidos Minerais e um Terminal de Carga Geral (madeiras, açúcar, algodão e cimento). Estes últimos dois terminais compartilharão um píer (Tpnr, 2015). Foi observado que a configuração do empreendimento apresenta de forma clara e 
objetiva como será toda sua infraestrutura por meio de texto e imagens, sendo uma realidade encontrada em outros RIMAs (Cargill, 2018; Ldc, 2020).

Além desta configuração, o empreendimento irá oferecer mão-de-obra para 426 trabalhadores para atuarem na instalação dos terminais. Por outro lado, o projeto prevê a contratação de 880 profissionais para atuarem na operação do terminal (Tpnr, 2015). Essa contratação irá promover o desenvolvimento socioeconômico na região por meio da atuação de profissionais de municípios vizinhos e, principalmente, de Itacoatiara/AM.

\subsubsection{Diagnóstico ambiental}

De modo geral, não foi observado nenhuma ilustração que apresente as áreas de influência, de forma que, promova a maior compreensão para os leitores em relação ao perímetro da área. Foi observado somente locais que englobam as áreas, sendo essencial a utilização de ilustrações para facilitar o entendimento ao público e identificar o perímetro das áreas analisadas, conforme supracita a Resolução CONAMA nº 01/1986 (Brasil, 1986).

\subsubsection{Meio físico}

Inicialmente, foi observado no Meio Físico as questões climáticas da região onde o Terminal Portuário será inserido. O presente RIMA não considera nenhum gráfico com os critérios interpretativos de temperatura e condições climáticas, conforme preconiza a Resolução CONAMA no 01/1986 (Brasil, 1986), sendo somente exposto a média anual. Longe dessa realidade, o RIMA Ldc (2020) apresenta informações detalhadas sobre o clima e a meteorologia, que contribuem significamente para o entendimento sobre as condições climáticas da região.

A descrição da geologia no RIMA não apresenta dados referenciados e, quanto aos solos, são definidas as existências e naturezas dos mesmos, bem como a utilização de imagens fotográficas referente as formações dos solos, conforme preconiza a Resolução CONAMA n ${ }^{\circ}$ 01/1986 (Brasil, 1986). Assim como o presente RIMA, foi observado as mesmas considerações no RIMA Ldc (2020) e RIMA Cargill (2018), apresentando informações importantes que contribuem para a compreensão do público leigo.

Quanto ao detalhamento das características hidrológicas do RIMA, não foi verificado os cursos d'água com ilustração fotográfica, podendo ser ilustrados por meio de mapas utilizando sensoriamento remoto. Foi possível observar que o presente item possui diversas informações importantes, como os igarapés presentes nas áreas de influência, imagens do local e análise da qualidade da água, na qual não foi observado variações nos parâmetros analisados. Algumas das informações apresentadas foram observadas no estudo de Oliveira (2018), na qual foi salientado a existência de mapas com cursos d'água, nome das planícies, imagens fotográficas e etc., na qual facilita a compreensão para os leitores leigos.

\subsubsection{Meio biótico}

Para o meio biótico, o RIMA apresenta falhas nas características florísticas, não apresentando informações concretas sobre os tipos de vegetação existente no local, por meio de nome popular e científico das espécies. O RIMA salienta apenas que a área do empreendimento possui uma cobertura de floresta nativa e de pastagem, agrícola e de padrão urbano, o que configura em ausência de clareza neste tópico. Longe dessa realidade, o RIMA Ldc (2020), apresentou em sua composição informações importantes sobre a área vegetal no terminal portuário, onde apresenta nomes populares e científicos de espécies vegetais da região, bem como ilustrações das vegetações (Ldc, 2020).

Quanto as caracterizações faunísticas presente no RIMA, foi observado que o mesmo possui um alto nível de detalhamento sobre as especificações, contendo nomes populares e científicos das espécies, bem como quantificação. Foi observado no RIMA de um Terminal Portuário de Uso Privado (Cargill, 2018) que as considerações do presente estudo estão 
similares ao mesmo, contendo um alto nível de detalhamento sobre as especificações, como os nomes populares e científicos das espécies, bem como imagens e quantificação de espécies. Esse alto nível de informação agrega principalmente na clareza e compreensão para leitores, bem como para o presente RIMA.

\subsubsection{Meio socioeconômico}

O meio socioeconômico do presente RIMA apresentou uma abundância de informações ricas nos meios históricos, geográficos, econômicos, de infraestruturas, patrimônios históricos, culturais e arqueológicos, bem como terras indígenas, envolvendo as áreas de uso e ocupação do solo, atividades econômicas da região, saneamento básico, educação, transporte, segurança pública e patrimônios intangíveis. Essas mesmas considerações foram apresentadas em outros RIMAs (Cargill, 2018; Ldc, 2020) caracterizando informações importantes para entender como funciona a socioeconômica na região a ser implantado o terminal portuário.

\subsubsection{Impactos ambientais}

A análise dos impactos ambientais do presente RIMA consistiu em uma abordagem quantitativa e qualitativa dos prováveis impactos referentes aos meios físico, biótico e antrópico, incluindo solos, recursos hídricos, qualidade do ar, vegetação, fauna, infraestrutura física e social das áreas afetadas pelo empreendimento, paisagem e outros (Tpnr, 2015).

Desta forma, não foi observado nenhuma abordagem que envolva os impactos ambientais nas fases de implantação e operação do empreendimento, tempo de incidência e métodos, técnicas e critérios utilizados para sua identificação. Longe desta realidade, o RIMA do Gasoduto Juruá/Urucu (Petrobras, 2008) e RIMA do Terminal de Uso Privado (Cargill, 2018) apresentaram uma análise completa dos impactos ambientais, contendo as fases de instalação e operação do empreendimento, magnitude e importância do impacto identificado, tempo e duração da ação do impacto, dimensão espacial, reversibilidade e o caráter do impacto. Essas informações são essenciais para o público leigo compreender detalhadamente os impactos decorrente da instalação e operação do empreendimento.

Ainda, os impactos ambientais nos meios físicos, bióticos e antrópicos descritos no presente RIMA são similares aos apresentados em outros RIMAs (Bc port, 2016; Cargill, 2018), a exemplo também do RIMA localizado no Rio Pará (Ldc, 2020) como alterações na qualidade do ar, recursos hídricos, fauna e na atividade econômica da região. Essa similaridade representa a veracidade de informações descritas em ambos relatórios situados na região Norte.

\subsubsection{Qualidade ambiental futura da área de influência}

Segundo a Resolução CONAMA nº 01/86 (Brasil, 1986), a qualidade ambiental futura é um dos requisitos mínimos que deve compor o RIMA, na qual, deve salientar as diferentes contribuições da adoção do projeto e suas tecnologias no local, bem como salientar a hipótese da não existência deste empreendimento.

Diante deste contexto, não foi observado nenhuma informação salientada anteriormente sobre a qualidade ambiental futura do empreendimento. A utilização destas informações e critérios utilizados são essenciais no RIMA, de forma a promover o conhecimento da comunidade sobre a abordagem de diferentes contribuições e tecnologias do empreendimento no local, bem como a possível não existência do mesmo, sendo falhas encontradas em outros relatórios de impacto sobre o meio ambiente (Terfron, 2005; Cargill, 2018).

Alguns Relatórios de Impactos sobre o Meio Ambiente apresentaram informações referente a alternativa da não implantação do empreendimento, bem como com o empreendimento, abordando critérios técnicos relevantes para adoção nos meios físicos, bióticos e socioeconômicos (Tepor, 2014; Ldc, 2020). 


\subsubsection{Medidas mitigadoras e programas ambientais}

Foi observado que as medidas mitigadoras são agrupadas com os programas ambientais. Essas informações descritas nos programas são claras e objetiva, uma vez que faz uma abordagem completa para minimização dos impactos negativos por meio destes programas, porém esse conjunto de informações não relaciona diretamente as medidas mitigadoras com os impactos negativos direto e indireto pelo empreendimento.

Para Duarte e Kakinami (2018), as medidas mitigadoras são agrupadas nos programas ambientais, uma vez que estes desenvolvem um conjunto de ações de forma racional e demais instrumentos relacionados para a garantia da efetividade dos mesmos. No presente estudo, foi observado este conjunto de ações para minimizar os eventuais impactos diretos e indiretos decorrentes do empreendimento, porém, não foi observado o direcionamento das medidas mitigadoras aos impactos gerados.

A resolução CONAMA nº 01/1986 (Brasil, 1986) salienta a importância de programas de acompanhamento e monitoramento dos impactos, contendo uma clareza e objetividade. Sendo assim, foi quantificado 12 programas ambientais importantes e fundamentais para garantia ambiental do empreendimento, sendo que alguns destes programas também já foram descritos em outros relatórios (Terfron, 2005; Tepor, 2014; Ldc, 2020). Porém, diversos programas ambientais com caráter de importância e significância para os empreendimentos portuários não foram agrupados ao conjunto descrito no presente relatório.

Alguns relatórios de impacto sobre o meio ambiente de terminais portuários (Terfron, 2005; Tepor, 2014; Ldc, 2020) apresentaram demais programas que são essenciais para assegurar a qualidade ambiental onde o empreendimento está inserido, sendo:

- Plano de Prevenção de Poluição das Águas Pluviais;

- Programa de Gestão Ambiental;

- Subprograma de Monitoramento e Controle do Ruído;

- Subprograma de Monitoramento e Controle da Qualidade do Ar;

- Subprograma de Gerenciamento de Efluentes;

- Subprograma de Gerenciamento de Resíduos Sólidos;

- Subprograma de Monitoramento da Qualidade da Água;

- Subprograma de Monitoramento de Sedimentos em ambiente de água doce.

- Programa de Monitoramento da Fauna Terrestre;

- Programa de Monitoramento da Biota Aquática;

- Programa de Controle de Processos Erosivos e Assoreamentos; e

- Estudo da Entomofauna Local com Ênfase nos Insetos e Pragas de Grãos Armazenados.

\subsubsection{Conclusões}

Segundo a Resolução CONAMA nº 01/86 (Brasil, 1986), o relatório de impacto sobre o meio ambiente deve apresentar ao final do conteúdo as recomendações, conclusões e comentários de ordem geral, de modo a assegurar finalmente, que o projeto atenderá do ponto de vista ambiental a minimização dos impactos descritos no EIA/RIMA.

Diante deste contexto, foi observado de modo geral que a conclusão descrita no presente relatório possui clareza e objetividade diante do exposto em tópicos anteriores, porém, falha na coerência, uma vez que destaca alguns impactos que o empreendimento poderá causar e garante a solução, mas não aborda ou mencionou nos programas ambientais aos quais realmente deveriam ser utilizados para minimizar estes impactos. 


\subsubsection{Equipe multidisciplinar}

Segundo Souza (2017) a equipe multidisciplinar deve ser abrangente e possuir profissionais de diversas áreas, como geólogos, geógrafos, engenheiros, advogados, biólogos, antropólogos, arqueólogos, sociólogos, médicos e outros. Por outro lado, a seleção de uma equipe multidisciplinar varia para cada projeto, devendo observar a necessidade do empreendimento, bem como a localização e em alguns casos o estabelecido pelo termo de referência (TR). Sendo assim, o Quadro 3 apresenta a quantificação dos profissionais que compõe a equipe multidisciplinar do presente RIMA.

Quadro 3: Quantificação dos profissionais que compõe a equipe multidisciplinar.

\begin{tabular}{|l|l|l|}
\hline Profissão & Quantidade & Função \\
\hline Biólogo (a) & 03 & Flora, Fauna Terrestre e Ecossistemas Aquáticos \\
\hline Socióloga & 01 & Meio Socioeconômico \\
\hline Geógrafo & 02 & Coordenação Técnica \\
\hline Jornalista & 01 & Jornalista responsável pelo RIMA \\
\hline
\end{tabular}

Fonte: Tpnr (2015).

A falta de diversos profissionais que atuem nas mais variadas áreas é evidente, na qual, apenas 7 profissionais foi averiguado, na sua maioria como biólogos atuando na elaboração do RIMA que trata de um terminal portuário a ser instalado no município de Itacoatiara/AM. Longe dessa realidade, alguns RIMAs apresentaram em sua equipe multidisciplinar diversos profissionais das mais variadas áreas de atuação, com titulação de bacharel, especialista e mestre nos meios físicos, bióticos e socioeconômicos, envolvendo engenheiros, historiadores, advogados, biólogos, geógrafos, oceanógrafos, sociólogos, Meteorologista e outros profissionais (Terfron, 2005; Tepor, 2014; Ldc, 2020). A presença de uma equipe multidisciplinar pode ter desafio de relacionar as diferentes problemáticas e linguagens de cada especialista na sua área, de forma a interpretar e avaliar os impactos decorrente do projeto e contribuir significativamente na elaboração de medidas mitigadoras, planos e programas ambientais para garantia da segurança ambiental do empreendimento (Souza, 2017).

\subsection{Síntese geral dos requisitos analisados}

A síntese geral dos requisitos analisados constitui na atribuição de duas variáveis, sendo "Não" para os itens que não satisfizeram os requisitos analisados e a palavra "Sim" para os itens que cumpriram os estabelecidos pelas resoluções ambientais vigorantes. O Quadro 4 apresenta a síntese geral dos requisitos analisados. 
Quadro 4: Apresentação da síntese geral dos requisitos analisados.

\begin{tabular}{|l|l|l|}
\hline \multirow{2}{*}{ Requisitos Analisados } & Atendimento aos requisitos \\
\cline { 2 - 3 } & Não & Sim \\
\hline Linguagem & $\mathrm{X}$ & \\
\hline Objetivos e Justificativas & & $\mathrm{X}$ \\
\hline Empreendimento & & $\mathrm{X}$ \\
\hline Diagnóstico Ambiental & & $\mathrm{X}$ \\
\hline Prováveis Impactos Ambientais & $\mathrm{X}$ & \\
\hline Qualidade ambiental futura da área de influência & $\mathrm{X}$ & $\mathrm{X}$ \\
\hline Medidas mitigadoras & & \\
\hline Programa de acompanhamento e monitoramento dos impactos & $\mathrm{X}$ & \\
\hline Conclusões & $\mathrm{X}$ & \\
\hline Equipe Multidisciplinar & $\mathrm{X}$ & \\
\hline
\end{tabular}

Fonte: Autores (2021).

A partir da exposição no Quadro 4, foi possível observar que 60\% dos requisitos analisados não estão de acordo com as recomendações mínimas da Resolução CONAMA nº 01/1986 (Brasil, 1986), desde a falta de uma linguagem simples, com presença de glossário no relatório até a necessidade de uma equipe multidisciplinar com profissionais de diversas áreas de atuação.

Esses resultados chamam atenção para a qualidade do RIMA, uma vez que as informações descritas no RIMA colocam em risco o entendimento do público leigo, bem como o meio ambiente, devido à ausência de prováveis impactos, delimitação da área de influência e programas ambientais para suprir os impactos. Essa ausência de informação deve ser fiscalizada diretamente por meio dos órgãos ambientais, de forma a não colocar em risco o meio ambiente e a população próxima a área a ser instalado o terminal. O resultado da síntese geral do presente RIMA é similar ao estudo de Oliveira (2018) onde analisou 5 RIMAs referente a empreendimento rodoviário federal, na qual 4 RIMAs apresentaram falhas na linguagem, percepção ambiental, diagnóstico ambiental e equipe multidisciplinar. Essas falhas são relacionadas diretamente pela ausência de informações necessárias para elaboração dos RIMAs por parte da equipe técnica, que mesmo possuindo muitas falhas, acabam sendo aprovadas para licenciamento devido não ocorrer fiscalizações rigorosas por órgãos ambientais (Oliveira, 2018).

\section{Considerações Finais}

Diante do estudo apresentado, percebe-se a importância da qualidade descrita no relatório de impacto sobre o meio ambiente, uma vez que estes são direcionados ao público leigo e demais profissionais, devendo conter informações objetivas, claras e coerentes com a realidade ao qual será inserido.

O presente RIMA apresentou falhas em $60 \%$ dos requisitos analisados, na qual, observou-se ausência de impactos negativos relacionados com o empreendimento, mapas e demais ilustrações, falta de programas ambientais e profissionais de áreas variadas atuantes no contexto do EIA/RIMA. Essas informações são requisitos mínimos salientados por resoluções vigentes e que merecem total atenção para a aprovação do referido documento, além da compreensão por parte da comunidade em geral.

É fundamental que os órgãos ambientais realizem uma análise criteriosa quanto as informações descritas no corpo do documento, bem como o quantitativo de profissionais responsáveis e, principalmente, comparando com as recomendações 
mínimas descritas em resoluções vigentes, para então serem licenciadas para aprovação. Após a aprovação, é fundamental a fiscalização rigorosa por parte dos órgãos ambientais, de modo que o empreendimento cumpra com as obrigações estabelecidas por legislações referentes ao licenciamento ambiental, de forma a minimizar os impactos ambientais gerados pelo empreendimento.

Para futuros estudos, sugere-se uma análise aprofundada dos impactos ambientais in loco nos meios biótico, físico e socioeconômico e a efetividades dos programas ambientais implementados no empreendimento, com intuito da garantia da minimização dos impactos sobre o meio ambiente.

\section{Referências}

Antaq. (2013). Indicadores do Transporte de Cargas: Tonelada Útil Transportada (T) d Tonelada Quilômetro Útil (TKU). ANTAQ.

Bc port. (2016). Relatório de Impacto Ambiental da Implantação do Terminal Portuário de Turismo BC PORT. ACQUAPLAN Tecnologia e Consultoria Ambiental.

Bertoloto, R. F. \& Mello, J. C. C. B. S. (2011). Eficiência de portos e terminais privados brasileiros com características distintas. Revista de Literatura dos Transportes, 5(2), 4-21.

Brasil. (2003). Lei $n^{\circ} 10.650$, de 16 de abril de 2003. Dispõe sobre o acesso público aos dados e informações existentes nos órgãos e entidades integrantes do Sisnama. Brasília, DF.

Cargill. (2018). Relatório de Impacto Ambiental Terminal Portuário De Uso Privado TUP Abaetetuba. Ambientare Soluções em Meio Ambiente.

Duarte, C. G. \& Kakinami, S. H. (2018). Impactos ambientais: análise e medidas. São Paulo: Editora Senac.

Eletronuclear. (2005). Identificação e avaliação dos impactos ambientais/medidas mitigadoras e compensatórias. http://www.eletronuclear.gov.br/Sociedadee-Meio-Ambiente/Documents/RIMA/07_identificacao.html

Guedes, L. E. M., Pena, R. C. M. \& Guerreiro, A. S. (2008). Análise de Eficiência dos Terminais Portuários do Mercosul. In: XXII ANPET, $319-330$.

Ibge. (2021). Censo 2010. https://censo2010.ibge.gov.br

Ldc. (2020). Relatório de Impacto Ambiental TUP LDC Rio Pará. ARCADIS Design \& Consultancy.

Marconi, M. D. \& Lakatos, E. M. (2003). Fundamentos da metodologia científica. Atlas.

Mohee, R., Surroop, D., Mudhoo, A. \& Rughooputh, B. K. (2012). Inventory of waste streams in an industrial port and planning for a port waste management system as per ISO14001. Ocean and Coastal Management, 61,10-19.

Monié, F. \& Vidal, S. M. S. C. (2006). Cidades, portos e cidades portuárias na era da integração produtiva. Rio de Janeiro, Revista de Administração Pública, 40(6), 975-995.

Moura, D. A. \& Botter, R. C. (2011). O transporte por cabotagem no Brasil - potencialidade para a intermodalidade visando a melhoria do fluxo logístico. Revista Produção Online, 11(2), 595-617.

Oliveira, C. M. (2015). Gestão ambiental portuária: uma análise sobre as políticas de mitigação e adaptação dos impactos socioambientais impostos às comunidades pesqueiras tradicionais. Monografia (Graduação em ciências econômicas) - Universidade Federal da Bahia, Salvador.

Oliveira, L. (2018). Análise da Qualidade dos Relatórios de Impactos Ambientais (RIMA's) de Empreendimentos Rodoviários Federais. Monografia (Graduação em Engenharia Florestal) - Universidade Federal de Sergipe, São Cristóvão.

Prodanov, C. C. \& Freitas, E. C. (2013). Metodologia do trabalho científico: métodos e técnicas da pesquisa e do trabalho acadêmico. Feevale.

Petrobras. (2008). Estudo Prévio de Impacto Ambiental para Construção do Gasoduto Juruá/Urucu (Relatório de Impacto Ambiental). Piatam instituto.

Pinheiro, L. V. S., Penãloza, V., Monteiro, D. L. C. \& Nascimento, J. C. H. B. (2014). Comportamento, crenças e valores ambientais: uma análise dos fatores que podem influenciar atitudes pró-ambientais de futuros administradores. Revista de Gestão Social e Ambiental, 8(1), 89-104.

Sakamoto, C. K. \& Silveira, I. O. (2014). Como Fazer Projetos de Iniciação Científica. Paulus.

Sánchez, L. E. (2013). Avaliação de impacto ambiental: conceitos e métodos. Oficina de Textos.

Scheidecker, C. (2018). Participação pública e gestão de conflitos. Editora Senac, São Paulo.

Souza, B. A. (2017). EIA-RIMA: estrutura geral e relações. Editora Senac.

Tepor. (2014). Relatório de Impacto Ambiental do Terminal Portuário de Macaé. Masterplan Consultoria de Projetos e Meio Ambiente. 
Research, Society and Development, v. 10, n. 10, e205101018750, 2021

(CC BY 4.0) | ISSN 2525-3409 | DOI: http://dx.doi.org/10.33448/rsd-v10i10.18750

Terfron. (2005). Relatório de Impacto Ambiental para a Implantação do Terminal Portuário Graneleiro de Barcarena/Pará. PLANAVE S. A. Estudos e Projetos de Engenharia.

Tpnr. (2015). Relatório de Impacto Ambiental: Terminal Portuário Novo Remanso, AM. JGP Consultoria e Participações. 